九州大学学術情報リポジトリ

Kyushu University Institutional Repository

\title{
Numerical and Experimental Quantification of the Performance of Microreactors for Scaling-up
} Fast Chemical Reactions

\section{Asano, Shusaku}

Department of Chemical Engineering, Kyoto University

Yatabe, Shota

Department of Chemical Engineering, Kyoto University

Maki, Taisuke

Department of Chemical Engineering, Kyoto University

Mae, Kazuhiro

Department of Chemical Engineering, Kyoto University

ht tp://hdl. hand le. net/2324/2244503

出版情報: Organic Process Research \& Development. 23 (5), pp.807-817，2019-05-17. American Chemical Society

バージョン:

権利関係 : 


\section{Numerical and experimental quantification of the}

\section{performance of microreactors for scaling-up fast}

\section{chemical reactions}

Shusaku Asano ${ }^{*}{ }^{\dagger}$, Shota Yatabe ${ }^{\dagger}$, Taisuke Maki ${ }^{\dagger}$ and Kazuhiro Mae ${ }^{\dagger}$.

${ }^{\dagger}$ Department of Chemical Engineering, Kyoto University, Kyoto 6158510, Japan

KEYWORDS. microreactor, mixing, heat removal, flash chemistry, kinetic analysis, scale-up. 


\section{TOC GRAPHIC}

For Table of Contents Only.
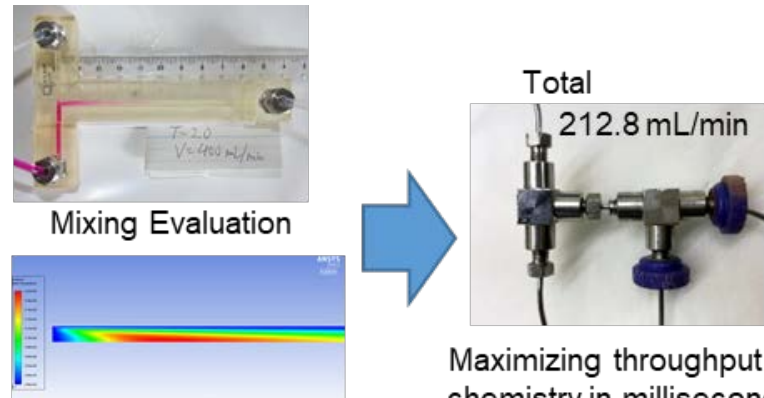

Heat Transfer Analysis

Maximizing throughput of chemistry in milliseconds 
ABSTRACT. Microreactors have been utilized for controlling fast chemical reactions. However, the scale-up strategy for fast reactions is not established enough due to the difficulty in quantifying the effect of the reactor size on the mixing performance, heat removal, and observable reaction rate. We present a chart for analyzing the effect of the mixing rate on the observable kinetic constant and a chart for estimating the temperature rise in the reactor. By using these charts, the validity of the rate analysis and the maximum reactor diameter, which control the reaction temperature, were determined. Commercial computational fluid dynamics (CFD) software was employed to solve the partial differential equations and to build the charts, and experiments were conducted to validate the results. We demonstrated the concept by using ultrafast organolithium reaction in milliseconds. The product throughput was increased 8 times with a reactor diameter that was twice as wide as the original reactor.

\section{INTRODUCTION}

The microreactor, a small-sized chemical reactor for continuous operation, has played a crucial role in the concepts of green chemistry and process intensification ${ }^{1,2}$. The continuous operation of microreactors enables industrial mass production with much smaller equipment compared to the conventional batch equipment. For example, FUJIFILM built a micro chemical plant for production of organic pigment suspension with $1 \mathrm{wt} \%$ concentration $^{3}$. It was reported that a micromixer with 50-200 $\mu \mathrm{m}$ channel diameter ${ }^{4}$ produced the suspension in the scale of 50 tons/year. MITSUBISHI RAYON also built a bench scale plant using microreactors ${ }^{5}$ for oxidative dehydrogenation of lactate to pyruvate ${ }^{6}$. Parallelized microreactors are used for oxidizing $0.1 \mathrm{~mol} / \mathrm{L}$ of ethyl lactate in acetonitrile with the flow rate of $860 \mathrm{~mL} / \mathrm{min}$. Industrial 
chemical production using a microreactor is beneficial for reducing plant size along with environmental footprint.

At the microscale, mass and heat transfer are dramatically improved by shorter diffusion lengths and high surface-to-volume ratios. Microreactors are now widely used for efficient multiphase reactions ${ }^{7}$, on-demand synthesis of pharmaceuticals ${ }^{8}$, fine particle synthesis ${ }^{9,10}$, and novel organic synthesis routes called flash chemistry ${ }^{11}$. The concept of flash chemistry is the utilization of short-lives intermediates before they convert to undesired products with the assistance of microreactors. Reactions involving organolithium compounds are mainly used in flash chemistry. By reducing the residence time, unstable organolithium compounds can be efficiently converted to desired products at around room temperature ${ }^{12}$, or without the introduction of protecting groups ${ }^{13}$.

Screening of the temperature and residence time using contour maps is often employed for optimizing reaction conditions in lab-scale flash chemistry. Comparison of the contour maps under different reaction conditions such as substrates $^{14}$ and mixing intensity ${ }^{15}$ has been meaningful and insightful for optimizing the conditions. However, this is not applicable when the reactor dimension is changed for increasing throughput. The reactor dimension influences both mixing and temperature profiles such that all the contour maps can change with the size enlargement. A systematic method for analyzing the effect of the microreactor dimension is essential for effectively implementing flash chemistry for mass production.

Two approaches, a fully model-based reactor design with rate analysis and a simple determination of acceptable maximum reactor size, are possible for scale-up. The fully modelbased approach according to reaction kinetics and rate equations is canonical for chemical 
engineers to design a reactor for industrial production. The model-based approach is beneficial to further optimize the reactor shape and operating conditions. Previous researchers have performed the design of microreactors based on rate analysis in moderately fast reactions ${ }^{16,17}$. In contrast, rate analysis has rarely been conducted for fast reactions involving organolithium compounds ${ }^{18}$. Roberge et al. recommended not kinetic analysis but black box modeling for a reaction faster than $1 \mathrm{~s}^{17}$. The difficulty lies in the reliability of kinetic parameter determination. Rate analysis is valid only when experiments are conducted under reaction-limited conditions. Microreactors have enabled fast reactions, but it is difficult to certify that the results obtained within a second were not affected by mixing at all. An evaluation protocol for whether experiments were in the reaction-limited condition or in the mixing-limited condition is needed.

On the other hand, the simple scale-up by linearly increasing both the reactor size and the flow rate is a more straightforward and easier approach. In this case, the maximum reactor size that can maintain the mixing and heat transfer performance should be analyzed to acquire the same reaction results. Mixing characterization in industrial reactors were often studied by using chemical test reaction systems such as Bourne reactions ${ }^{19,20}$ and Villermaux-Dushman reaction system $^{21}$. Because of their convenience in evaluating mixing performance with changing the mixer geometry and operating conditions, many studies on micromixers have been done with these reaction systems ${ }^{22-24}$. A linear correlation based on the kinetic model is used to convert the test results to the mixing times ${ }^{25,26}$. However, our recent study ${ }^{27}$ as well as the discussions on the Villermaux-Dushman reaction system by Kölbl and $\mathrm{Kraut}^{28}$ proved that the actual mixing time could differ by an order of magnitude from the estimation based on the chemical test reaction systems owing to the complex reaction profiles inside the microreactors. Many studies using computational fluid dynamics (CFD) simulations have revealed important factors for mixer 
design $^{29-32}$, though, these studies based on CFD simulations are generally focusing on the complex convection phenomena occurring in a specific mixer with a fixed size. An easy-to-use relationship for determining mixing time from mixer size and operating condition is merely found to the best of our knowledge. Regarding the characterization of the heat transfer performance, Baldyga et al. modeled the non-isothermal micromixing to formularize the effect of temperature rise on the results of the Bourne reactions ${ }^{33}$. Because the temperature rise played a minor and unimportant role in the Bourne reactions compared to the mixing ${ }^{33,34}$, their function as a probe for temperature rise is rather qualitative ${ }^{35}$ and is affected by the coupled mixing behavior ${ }^{36}$. Analytical methods rather than chemical test reactions have been more favored and successfully utilized to discuss the heat removal in a microreactor. For instance, Kockmann and Roberge ${ }^{37}$ proposed criteria for obtaining the maximum reactor diameter for avoiding thermal runaway based on the parametric sensitivity analysis. Even so, another criterion is needed for treating fast organic reactions. For example, organolithium reactions in a solvent rarely suffer from thermal runaway due to the heat capacity of the solvent and the limited amount of the reactant. However, the reaction selectivity of the organolithium reaction can be dramatically changed by a temperature difference of only $5 \mathrm{~K}^{38}$. The actual temperature rise in a microreactor from the set temperature should be known for conducting and analyzing the reaction properly. The temperature rise in a tubular reactor was well studied and formulated decades ago ${ }^{39}$, however, these equations necessarily require the activation energy for calculation. The activation energy of the organic reaction studied in a laboratory is hardly obtained. As a result, classical equations are not useful for many practical situations of research and development of organic chemistry involving a microreactor. 
This study aimed to suggest procedures for the quantitative analysis of the mixing and heat transfer problems in a microreactor for scaling-up fast $(<1 \mathrm{~s})$ and ultrafast $(<10 \mathrm{~ms})$ chemical reactions. The first section is dedicated to the kinetic analysis. A theoretical analysis was conducted to construct a simplified model. The partial differential equations (PDEs) derived from the model was solved by a commercial CFD software. Dimensionless numbers were used to build a chart to determine whether the reaction was in the reaction-limited condition or in the mixing-limited condition. The second section features the determination of the maximum reactor diameter for satisfying the mixing and heat transfer performances for reaction control. The temperature rise in the reactor was numerically solved and analyzed using a dimensionless number. Scale-up of the ultrafast organolithium reaction was demonstrated using the results in the second section.

\section{EXPERIMENTS AND SIMULATIONS}

Materials. Mesityl bromide (MesBr), p-iodoacetophenone (p-IAP), acetophenone (AP), $n$ undecane, a $1.6 \mathrm{M}$ solution of $n$-butyllithium ( $n$-BuLi) in hexane, phenolphthalein (PP), ammonium chloride, ethanol, methanol, tetrahydrofuran (THF), and hexane were purchased from FUJIFILM Wako Pure Chemical Corporation (Osaka, Japan) and used without further purification. A super dehydrated grade solvent was used for the organolithium reactions. Ultrapurified water was prepared using a Milli-Q water purification system (Millipore, Milford, MA, USA) and used throughout the experiment.

Numerical analysis of the mixing with reaction. The relationship between the mixing rate and the observable reaction rate was evaluated by numerically solving PDEs for a simplified situation. The mixing and the reaction in a $2 \mathrm{D}$ multilamination (2D ML) mixer, which is an 
idealized model of laminar mixing in a microreactor ${ }^{40}$, were considered. Figure 1 shows the schematics of the 2D ML mixer. Fluids A and B flowed into the reactor in a laminar form in the 2D ML mixer. The width of the lamina, $W_{2 \mathrm{D}}$, determined how the mixing and the reaction proceeded. We simulated a constant-volume liquid phase reaction triggered by the mixing of fluids A and B. Both fluids had the same physical properties and flow rate. The density and viscosity of the fluids were set to be equal to those of water at room temperature: $1000 \mathrm{~kg} \mathrm{~m}^{-3}$ and $0.001 \mathrm{~Pa} \mathrm{~s}$, respectively. The diffusivity of each species in the solution, $D$, was $10^{-9} \mathrm{~m}^{2} \mathrm{~s}^{-1}$. The reaction formulas, rate equations, and initial concentrations are given below:

$$
\mathrm{A}+\mathrm{B} \rightarrow 2 \mathrm{R}, r=k C_{\mathrm{A}} C_{\mathrm{B}}
$$

where $r$ and $k$ are the reaction rate and the rate constant, respectively; $C_{j}$ is the molar concentration of species $j$. The initial concentration of species A, $C_{\mathrm{A} 0}$, was set to $0.001 \mathrm{kmol} \mathrm{m}^{-3}$. Note that the concentration of $\mathrm{A}$ in the feed solution is the twice of $C_{\mathrm{A} 0}$. The initial concentrations of species $\mathrm{B}$ in the feed solution and thus $C_{\mathrm{B} 0}$ were changed for each calculation.

The commercial code for CFD simulations, ANSYS FLUENT 13.0 were employed for solving PDEs. The calculations were carried out with a laminar flow model in a steady state. The calculation space was discretized in 108000 rectangular grid elements. No mesh dependency was confirmed by refining the mesh to 432000 elements after each calculation. 


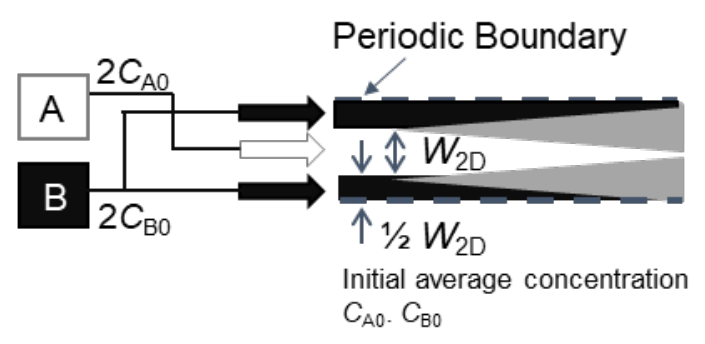

Figure 1. 2D ML mixer for CFD simulation of the mixing with reaction.

In-line measurement of the phenolphthalein decolorization. A base solution colored with phenolphthalein (PP) and an acid solution were mixed so that the pink color disappeared with the progress of mixing. The concentrations were as follows:

Acid solution; $[\mathrm{HCl}]=12 \mathrm{mM}$.

Base solution; $[\mathrm{NaOH}]=10 \mathrm{mM},[\mathrm{PP}]=0.26 \mathrm{mM}$.

The PP molecules presented a pink color upon releasing two protons under basic conditions. Neutralization of the solution made deprotonated molecules $\left(\mathrm{PP}^{2-}\right)$ disappear according to the reaction shown in Scheme 1. The kinetic analysis of the decolorization reaction was conducted as the pseudo first-order reaction of phenolphthalein and water ${ }^{41}$. The kinetic constant $k$ at $15^{\circ} \mathrm{C}$ was reported to be $4.7 \times 10^{4} \mathrm{~s}^{-1}$.

Scheme 1. Decolorization reaction involving phenolphthalein (PP).

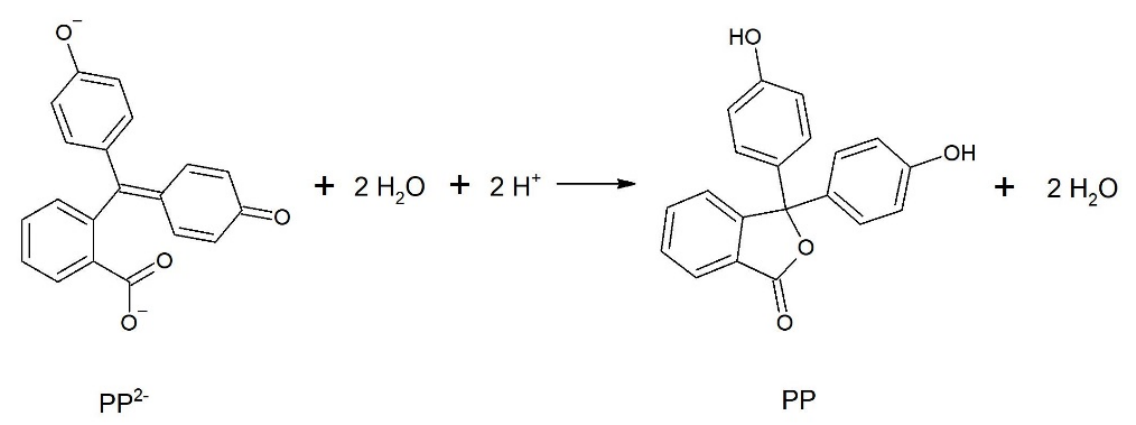


The solutions were fed into a device using PHD ULTRA syringe pumps (Harvard Apparatus, MA, USA) at room temperature. The device was made of polydimethylsiloxane and was fabricated by Fluidware Technologies (Saitama, Japan). The geometry of the device is shown in Figure 2.

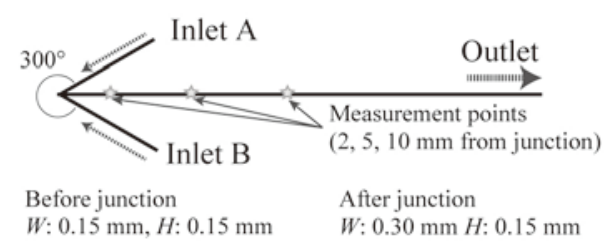

Figure 2. V-shaped microchannel for the in-line measurement.

The channel cross section was a rectangle that was $0.30 \mathrm{~mm}$ in width and $0.15 \mathrm{~mm}$ in height. The device was placed on the measurement stand of the portable UV-Vis spectrophotometer (MV-3100, JASCO, Tokyo, Japan). The measurement point was set at 2, 5, or $10 \mathrm{~mm}$ from the confluence point. The absorbance of deprotonated PP at $550 \mathrm{~nm}$ was measured after at least 1 min of operation. The channel was filled with the base solution, and the absorbance value (ABS) was measured before each experiment. The conversion of $\mathrm{PP}^{2-}$ was calculated using the following equation:

Conversion of $\mathrm{PP}^{2-}=\frac{\text { measured } \mathrm{ABS} \text { during experiment } \times \text { total flow rate }}{\mathrm{ABS} \text { before experiment } \times \text { flow rate of base solution }}$

The Reynolds number (Re) was used to analyze the results. Re is a dimensionless number defined as the ratio of the inertial force to the viscous force working on the flowing fluid. Re is calculated as:

$$
\operatorname{Re}=\frac{\rho v_{\mathrm{ave}} d}{\mu}
$$


where $\rho$ is the density of the fluid, $v_{\text {ave }}$ is the average velocity of the fluid, $d$ is the diameter of the reactor, and $\mu$ is the viscosity of the fluid. The hydraulic diameter calculated from the crosssectional area and the wetted perimeter of the cross-section was used for $d$ in noncircular channels.

Mixing time measurement in tee mixers. The same amounts of $12 \mathrm{mM} \mathrm{HCl}$ solution and 10 $\mathrm{mM} \mathrm{NaOH}$ solution were mixed with $1 \mathrm{mM}$ PP in transparent tee mixers to measure the mixing times. Three mixers with varying dimensions (T-0.5, T-1.1, and T-2.0) were evaluated. Photos were taken using a digital single-lens reflex camera (D50, Nikon, Tokyo, Japan). We estimated the mixing time $\left(t_{\mathrm{mix}}\right)$ from the decolorization length, $L_{\mathrm{mix}}$, and the average velocity ( $\left.v_{\text {ave }}\right)$ as follows:

$$
t_{\text {mix }}=\frac{L_{\text {mix }}}{v_{\text {ave }}}
$$

where $L_{\text {mix }}$ was derived from the procedure employed by Lim et $\mathrm{al}^{42}$. Because the PP solution appeared as pink, a complementary green channel in the RGB image was used for tracing the decolorization. The intensity profile with a green channel along the center of the tee channel was analyzed using ImageJ (NIH, USA). First, the intensity difference between the flow at the confluence point and the completely mixed flow far downstream was obtained. Then, the mixing point was defined as the point at which the intensity difference from the nozzle satisfied $90 \%$ of the previously obtained value. The $90 \%$ value was defined to avoid the error caused by small signal-to-noise ratio around $100 \%$. Then, $L_{\text {mix }}$ was calculated as the length from the T-junctions. An example of the analysis is shown in Figure S1 in the supporting information. At least three photographs were taken and the average length was used for calculation. 
Tee-0.5, a tee mixer with a square channel of $0.50 \times 0.50 \mathrm{~mm}$, was fabricated by Fluidware Technologies. The larger mixers, Tee-1.1 and Tee-2.0, were directly printed from a computer design using an inkjet 3D printer (Agilista, Keyence, Osaka, Japan) with UV curable transparent acrylate polymer (AR-M2, Keyence). The printer featured a resolution of $635 \mathrm{dpi}$ in the $x$ direction, $400 \mathrm{dpi}$ in the $y$-direction, and $15 \mu \mathrm{m}$ in the z-direction. After the experiments, the mixers were cut and the actual dimensions of the channel were measured. The measured dimensions of the channels were as follows:

Tee-1.1; $W 1.19 \mathrm{~mm} \times H 0.95 \mathrm{~mm}$.

Tee-2.0; $W 1.92 \mathrm{~mm} \times H 2.18 \mathrm{~mm}$.

The hydraulic diameters were used for calculating Re at each condition.

Numerical analysis of an exothermic reaction with heat removal. The relationship between the reactor dimensions and temperature rise in the reactors was evaluated by solving PDEs using FLUENT 13.0. Laminar flow in a tubular reactor was simulated with a 2D calculation space with an axisymmetric center and an isothermal wall, as shown in Figure 3. The fluid was fed into the reactor inlet with the parabola velocity profile of well-developed laminar flow. The first-order reaction, or the second-order reaction, as shown below, were simulated:

$\mathrm{A} \rightarrow \mathrm{R}, r=k C_{\mathrm{A}}, \Delta H_{\mathrm{r}}=-100 \mathrm{~kJ} \mathrm{~mol}^{-1}$

$\mathrm{A} \rightarrow \mathrm{R}, r=k C_{\mathrm{A}}^{2}, \Delta H_{\mathrm{r}}=-100 \mathrm{~kJ} \mathrm{~mol}^{-1}$

where $\Delta H_{\mathrm{r}}$ is the reaction enthalpy. All physical properties were set as constants independent on the temperature. The density, viscosity, thermal conductivity, and heat capacity of the fluids 
were $1000 \mathrm{~kg} \mathrm{~m}^{-3}, 0.001 \mathrm{~Pa} \mathrm{~s}, 0.6 \mathrm{~W} \mathrm{~m}^{-1} \mathrm{~K}^{-1}$ and $4182 \mathrm{~J} \mathrm{~kg}^{-1} \mathrm{~K}^{-1}$, respectively. The initial concentration of A was fixed to be $1.05 \mathrm{~mol} / \mathrm{L}$. The resulting adiabatic temperature rise was $25 \mathrm{~K}$. The wall temperature was set to 298 K. Physical properties of water except the viscosity don’t change so much with the temperature rise from $298 \mathrm{~K}$ to $323 \mathrm{~K}^{43}$, supporting the assumption of the constant physical properties. The maximum temperature rise along the center axis was evaluated by varying the reactor radius and the kinetic constant. A total of 80000 rectangular grid elements were used for discretization. No mesh dependency was confirmed by refining the mesh to 320000 elements after each calculation.

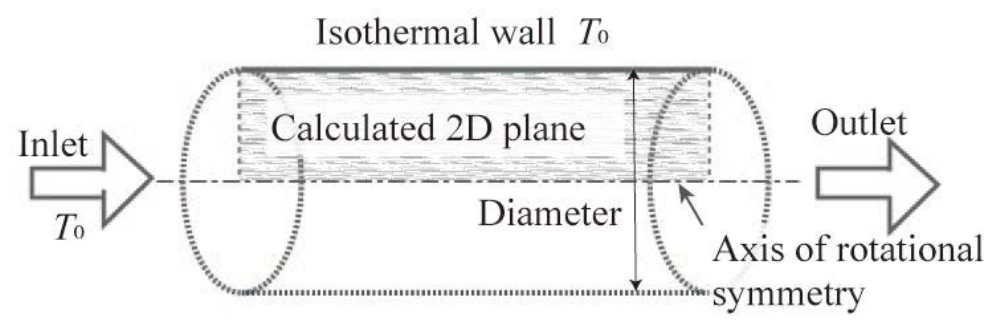

Figure 3. Tubular microchannel with an isothermal wall for numerical analysis of the exothermic reaction.

Protecting-group-free organolithium reaction with $p$-iodoacetophenone. A halogen-lithium exchange reaction to the substrate bearing the ketone carbonyl group without protection was carried out according to the procedure reported by Kim et $\mathrm{al}^{13}$. The reaction scheme is shown in Scheme 2. p-IAP was instantly converted to $p$-acetyl-phenyllithium ( $p$-APLi) by mesityllithium (MesLi). p-APLi easily attacked the unprotected ketone carbonyl group of another p-APLi molecule to produce byproducts. However, by sequentially adding electrophiles such as methanol within a timescale of milliseconds, desired products corresponding to the used electrophiles were obtained with a yield of up to $76 \%$. 
Scheme 2. Ultrafast halogen-lithium exchange reaction conducted in this study.

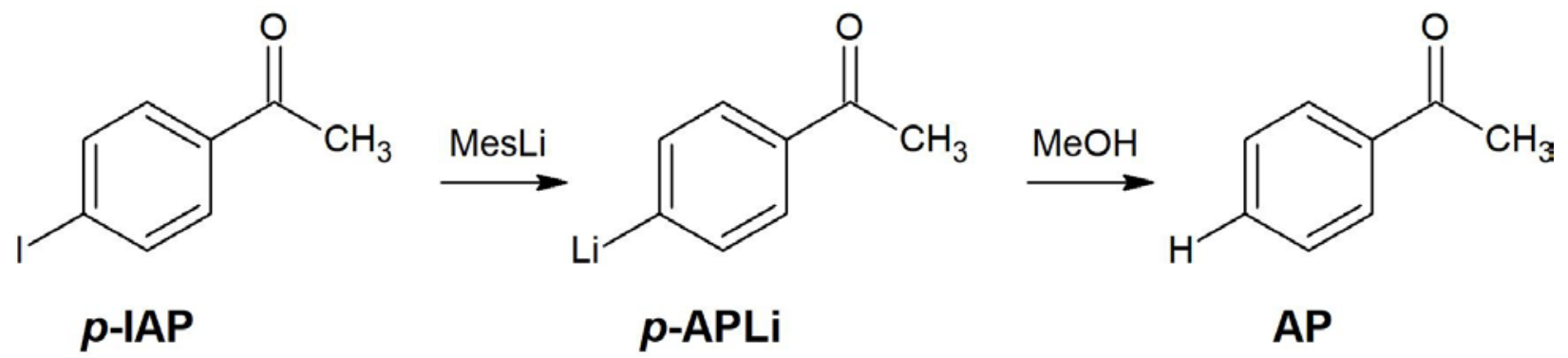

The reaction was conducted with a flow reactor system consisting of three T-mixers and stainless-steel tubing, as shown in Figure 4.

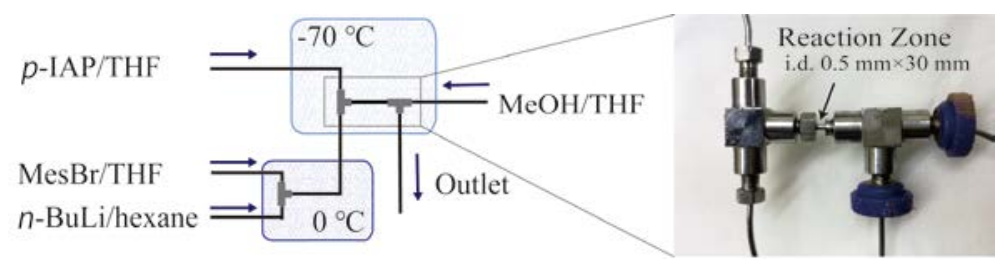

Figure 4. Reactor system for the ultrafast halogen-lithium exchange reaction

The first mixer was for the in situ generation of MesLi from n-BuLi and MesBr. The second mixer was for converting $p$-IAP to $p$-APLi. The third mixer was for trapping $p$-APLi with methanol to obtain AP. All the mixers had an internal diameter of $0.5 \mathrm{~mm}$. Stainless tubing between the second and third mixers was regarded as the "reactor." The reactor tubing was 3.0 $\mathrm{cm}$ in length and had an internal diameter of $0.5 \mathrm{~mm}$. Tee mixers with an inner diameter of 0.50 mm (U-428, IDEX Health \& Science) and stainless steel tubing with an inner diameter of 0.50 mm (1/16CT-4, GL Science, Tokyo, Japan) were used. The tubing was connected with a nut for space-limited applications (F-354, IDEX Health \& Science) and a standard nut (U-400, IDEX Health \& Science; 6010-48710, GL Science). A mixture of $0.18 \mathrm{M}$ of MesBr in THF, $0.43 \mathrm{M}$ of $n$-BuLi in hexane, $0.20 \mathrm{M}$ of $p$-IAP in THF, and $0.60 \mathrm{M} \mathrm{MeOH}$ in THF was fed into the device 
with a flow rate ratio of $5: 1.8: 3: 2$. The resulting molar ratio in the mixture is $\operatorname{MesBr} 1.5: n$ BuLi 1.3: p-IAP 1: methanol 2. MesLi was formed using MesBr surplus and p-APLi was formed using MesLi formed. Methanol oversupply converted all of $p$-APLi and MesLi. $n$-Undecane was added to the $p$-IAP solution at a concentration of $5 \mathrm{mM}$ for the inertial internal standard. 260D syringe pumps (Teledyne Isco, Lincoln, USA) were used for feeding solutions. The temperature of the device was controlled by immersing the first mixer in an ice bath at $0^{\circ} \mathrm{C}$ and immersing the second and third mixers in an acetone bath at $-70^{\circ} \mathrm{C}$. Stainless steel tubing with an i.d. of $1 \mathrm{~mm}$ and a length of 0.5-2 $\mathrm{m}$ was connected to the inlet of the mixers for cooling down the fluid to the set temperature. The produced solution was collected in a vial that held a saturated $\mathrm{NH}_{4} \mathrm{Cl}$ aqueous solution for aqueous workup. The organic solution was then analyzed by gas chromatography. A GC-2010 (SHIMADZU, Kyoto, Japan) system equipped with a flame ionization detector was employed with a fused silica capillary column (SHIMADZU, CBP-1). The temperature of the oven was increased from 50 to $280^{\circ} \mathrm{C}$ at a rate of $10^{\circ} \mathrm{C} \mathrm{min}{ }^{-1}$. The conversion of $p$-IAP and yield of AP were obtained from the calibration curve acquired as the area ratio to the $n$-undecane. Neither qualification nor quantification of side products were conducted because up to 20 small peaks of unknown species were observed in chromatograms of the obtained solution. The plausible paths for side products are reaction occurring ketone group and lithio group to generate oligomers, deprotonation and radicalization reactions of the $p$-APLi to generate fragmented species.

\section{VALIDATION METHOD FOR THE RATE ANALYSIS OF FAST REACTIONS}

Influence of mixing on the observable reaction rate of fast chemical reactions. We simulated the influence of mixing on quasi-first order reaction and second order reaction by changing the 
$\frac{C_{\mathrm{B} 0}}{C_{\mathrm{A} 0}}$ in the 2D ML mixer shown in Figure 1. Figure 5(a) presents the typical results for the quasifirst order reaction, $\frac{C_{\mathrm{B} 0}}{C_{\mathrm{A} 0}}=100$. The concentration profiles of reactant $\mathrm{A}$ in the $2 \mathrm{D} \mathrm{ML}$ mixer are shown for different lamella widths. Because the concentration of reactant B was 100 times larger than that of reactant $\mathrm{A}$, the slope of the concentration profiles in the semi-logarithmic plot can be regarded as the observable kinetic constant in the pseudo first-order reaction of reactant $\mathrm{A}$. If the mixing is ideally fast and perfect, the slope of the concentration profile should be equal to $-k C_{\mathrm{B} 0}$ $\left(=-100 \mathrm{~s}^{-1}\right)$. In the case of $2.5 \mu \mathrm{m}$ lamellae, the slope was $-97 \mathrm{~s}^{-1}$. The situation can be regarded as an almost ideal reaction-controlled scheme. In contrast, with $100 \mu \mathrm{m}$ lamellae, the value decreased to $-5.8 \mathrm{~s}^{-1}$. The situation can be regarded as undesirable diffusion-controlled scheme. The intermediate value of $-35.7 \mathrm{~s}^{-1}$ was observed with the strong curvature in the case of $25 \mu \mathrm{m}$ lamellae, indicating the intermediate situation between mixing controlled scheme and reactioncontrolled scheme. In the 2D ML model, only two dimensionless variables are essential for quantifying the influence of the mixing on the observable kinetic constant. The Damköhler number $\phi$ defined as $\frac{k C_{\mathrm{B} 0} W_{2 \mathrm{D}}^{2}}{D}$ and the feed concentration ratio $\frac{C_{\mathrm{B} 0}}{C_{\mathrm{A} 0}}$ were determined as key variables for determining the ratio of observable kinetic constant to the true kinetic constant, $\frac{k_{\mathrm{obs}}}{k}$. Derivation of dimensionless variables from the partial differential equations is explained in the supporting information. We defined $\frac{k_{\mathrm{obs}}}{k}$ as the effectiveness factor $\eta \cdot \eta=1$ means that mixing is enough faster than the reaction so the reaction rate is not influenced by the mass transfer. If mixing becomes slower compared to the reaction kinetics, $\eta$ value decreases and the reaction rate is dominated by the mass transfer. Figure 5(b) summarizes the simulation results in the $2 \mathrm{D}$ ML model for various $\phi$ and $\frac{C_{\mathrm{B} 0}}{C_{\mathrm{A} 0}}$. The cases of $\frac{C_{\mathrm{B} 0}}{C_{\mathrm{A} 0}}=100$ and $\frac{C_{\mathrm{B} 0}}{C_{\mathrm{A} 0}}=10$ are both regarded as the quasi- 
first order reaction but with the different diffusion flux value. $\frac{C_{\mathrm{B} 0}}{C_{\mathrm{A} 0}}=1$ is the case of second order reaction. The calculation procedure of the $k_{\mathrm{obs}}$ from the simulation results is described in the supporting information.
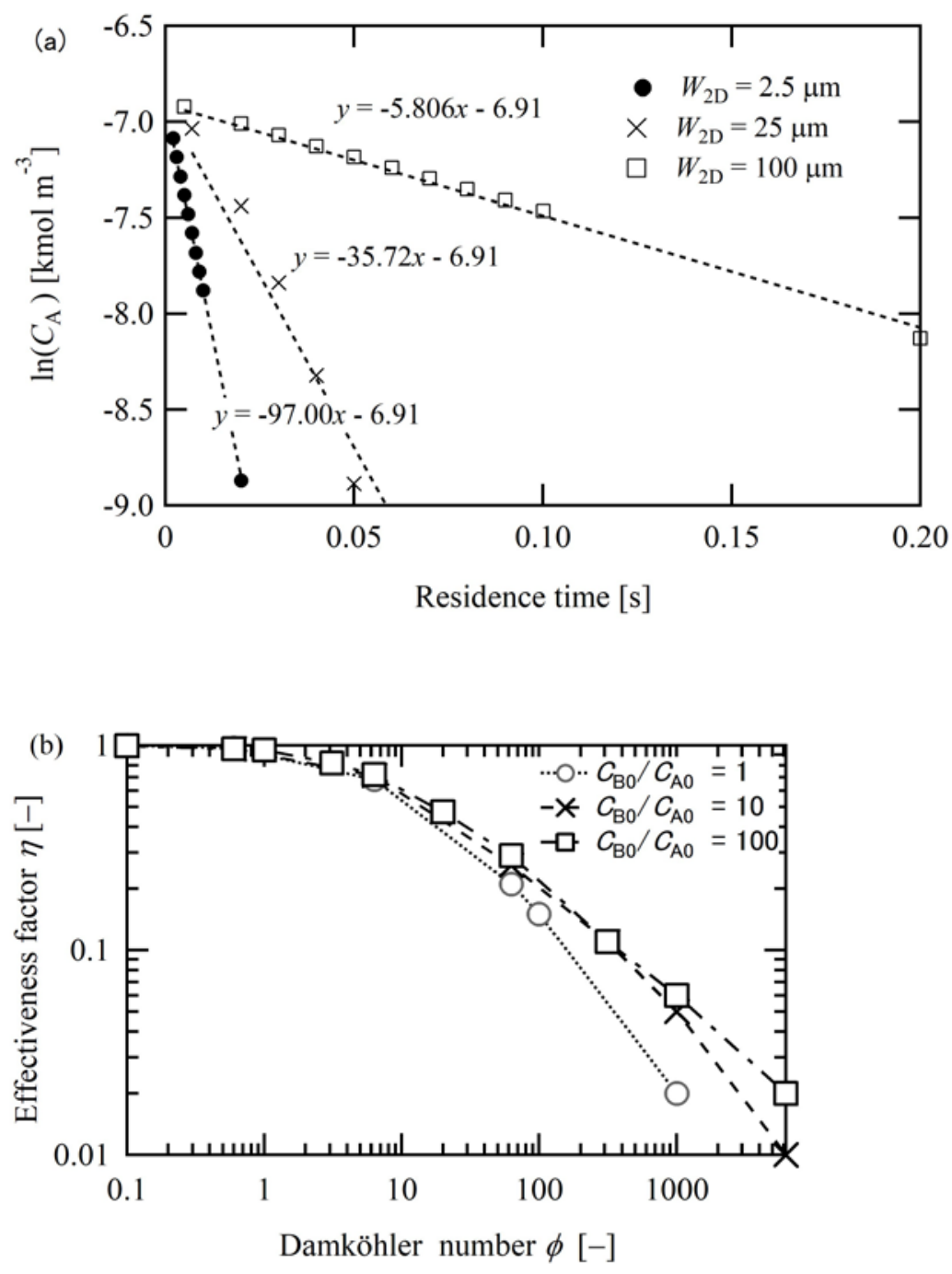

Figure 5. Simulation results in 2D ML mixers: (a) Semi-logarithmic plot of the concentration profiles of reactant A with $C_{\mathrm{B} 0}=0.1 \mathrm{kmol} \mathrm{m}^{-3}$, and $k=1000 \mathrm{~m}^{3} \mathrm{kmol}^{-1} \mathrm{~s}^{-1}$; (b) Relationship between the dimensionless variables and the effectiveness factor obtained by changing $k$ and $C_{\mathrm{Bm}}$. 
The profile of the chart was similar to that of the effectiveness factor and the Thiele modulus for solid catalyzed reactions ${ }^{44}$. The similarity would be because both are problems of diffusion and reaction. In both cases of the second-order reaction kinetics and the pseudo first-order reaction kinetics, the shapes of the profile were similar. The larger value of $\frac{C_{\mathrm{B} 0}}{C_{\mathrm{A} 0}}$ only resulted in slight larger value of $\eta$ in the high $\phi$ area. The value of $\eta$ was almost 1 at $\phi=1$ regardless of the value of $\alpha$. This means that the obtained kinetic constant is reliable if $\phi$ is less than 1 . The chart would be a useful tool for determining the reliability of the kinetic analysis.

Determination of the dimensionless numbers using in-line measurement. To verify the obtained relationship and its usage in realistic conditions, we conducted a case study of kinetic analysis with in-line measurements. The decolorization reaction of $\mathrm{PP}^{2-}$ with neutralization shown in Scheme 1 was chosen as the model reaction. The reaction can be regarded as a quasifirst-order reaction in acidic conditions. In this case, the main reactant A was phenolphthalein and the other reactant B was water with surpassing amount. The decolorization reaction has advantages due to its simplicity, the known kinetic constants, and a strong characteristic absorbance peak that is easy to measure with in-line spectroscopy. The V-shaped transparent microchannel was placed on the measurement stand of the UV-Vis spectrophotometer to detect the concentration of the remaining $\mathrm{PP}^{2-}$. We evaluated the reaction profiles by changing the total flow rate of the solutions and the measurement point. Figure 6 presents the obtained profiles with a total flow rate of $6-12 \mathrm{~mL} \mathrm{~min}{ }^{-1}$. With the lower flow rates, the curve was stepwise and completely different from the linear profiles presented in Figure 5. The mismatch would be caused by the discrepancy between the model considering uniform sized lamellae, and the real fluid dynamics inside the mixer. In fact, the stepwise profile agreed well with our previous computational study on the mixing and reaction with moderate Re in a microchannel with a 
confluence point ${ }^{29}$. We'd like to note that diffusion in the fully developed laminar flow after the disturbance is slow and hardly achieved within the residence time in the reactor. Mixing incompletion in this regime has been confirmed in the following section, as well as our previous CFD study ${ }^{32}$. Additional mixing structure, such as bending structures ${ }^{45}$ is needed for achieving mixing completion in this regime. In contrast, when the flow rate was high at $12 \mathrm{~mL} \mathrm{~min}^{-1}$, the profile was almost a simple exponential decay curve similar to Figure 5. The mixing profile, which was linear in a semi-logarithmic plot, would be caused by the chaotic mixing at higher $\mathrm{Re}^{46}$. The observable kinetic constant at $12 \mathrm{~mL} \mathrm{~min}^{-1}$ was $1.34 \times 10^{3} \mathrm{~s}^{-1}$. In this case, $\eta$ was determined to be 0.029 from the reported true kinetic constant of $4.7 \times 10^{4} \mathrm{~s}^{-1} . \phi$ was then derived to be $3 \times 10^{3}$ from Figure 5(b) using the curve for $\frac{C_{\mathrm{B} 0}}{C_{\mathrm{A} 0}}=100$ considering that the decolorization was a pseudo first-order reaction with water. The corresponding $W_{2 \mathrm{D}}$ value in the 2D ML model was obtained to be $8 \mu \mathrm{m}$ by substituting $D=10^{-9} \mathrm{~m}^{2} \mathrm{~s}^{-1}, \phi=3 \times 10^{3}$, and $k C_{\mathrm{B} 0}=4.7 \times 10^{4} \mathrm{~s}^{-1}$ to $\phi=\frac{k C_{\mathrm{B} 0} W_{2 \mathrm{D}}^{2}}{D}$. The maximum $k$ value that satisfies $\phi \leq 1$ was calculated to be $16 \mathrm{~s}^{-1}$. In summary, the 2D ML model focusing only on the diffusion is simplified but applicable for the practical convective mixer when the flow rate is high enough. This would be because intense vortices at the junction divide the fluids into the micro segments at once. Note that we think that $8 \mu \mathrm{m}$ is a quite reasonable value for the diffusion length of the fluids mixed in the micromixer from our previous studies. Experimentally, we have compared the mixing performance of micromixers with fluid collision to a micromixer with interdigital fluid division ${ }^{4}$. It showed that a tee mixer with an inner diameter of $1.6 \mathrm{~mm}$ and with high flow rate had similar mixing performance to an interdigital mixer with slit width of a $40 \mu \mathrm{m}$ and with small flow rate, implying that fluid collision can divide the fluid to segments as small as fortieth of the channel diameter. Other 
studies using CFD simulations ${ }^{29}$ elaborating vortices in tee mixer $(H=100 \mu \mathrm{m}, W=200 \mu \mathrm{m})$ confirmed that intense collision at the junction broke down the fluids to segments below $10 \mu \mathrm{m}$.

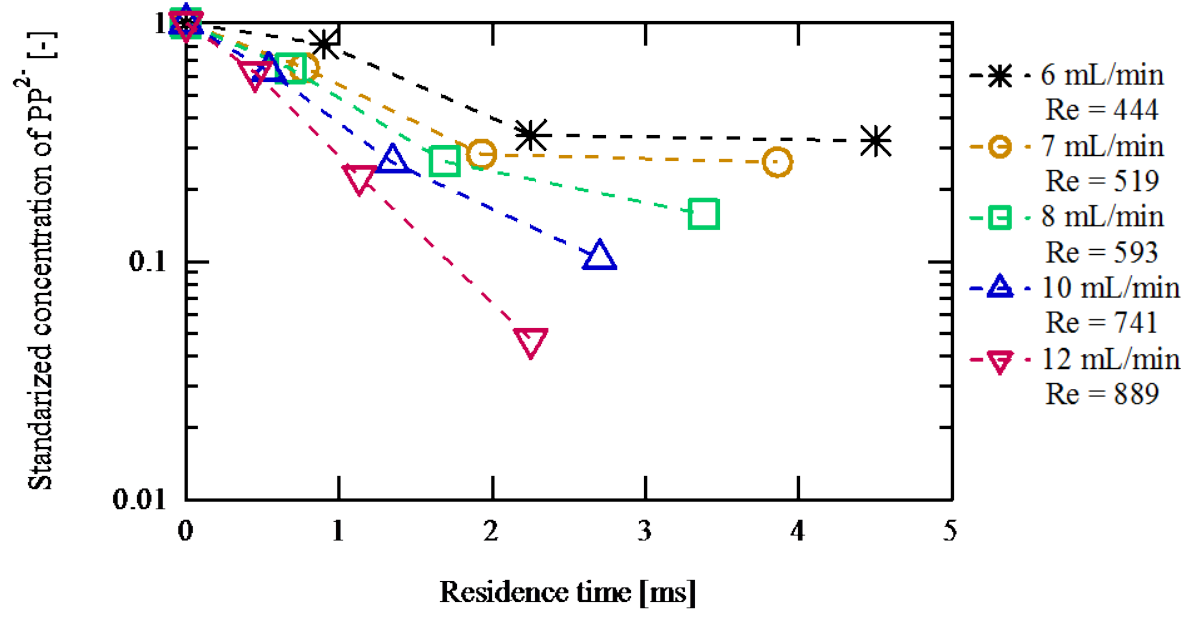

Figure 6. Protonation profile of $\mathrm{PP}^{2-}$ in a V-shaped micromixer. Dotted lines represent the fitted exponential curves.

\section{SIMPLE SCALE-UP STRATEGY OF FAST REACTIONS}

In this section, we discuss a simple procedure to scale-up fast and ultrafast chemical reactions that were successfully conducted in a microreactor. The advantages of microreactors in homogeneous reactions are the rapid mixing and heat transfer. We evaluated both properties with different scales to obtain the maximum reactor diameter that can maintain the required heat and mass transfer performance.

Mixing time evaluation with mixer scales. The mixing times in tee mixers with various dimensions were evaluated using the decolorization of $\mathrm{PP}^{2-}$. Not the in-line UV-Vis spectroscopy but a regular digital camera and image analysis were employed in this section for their simplicity. Figure 7 shows the results against the flow rate and Re. A flow rate range of $10-400 \mathrm{~mL} \mathrm{~min}^{-1}$ 
was evaluated. As shown in Figure 7(a), both an increase in the flow rate and a reduction in the mixer size shortened the mixing time. As shown in Figure 7(b), the mixing time profiles against Re were analogous in all three mixers. The mixing time shortened dramatically with the increase of $\operatorname{Re}$ at the range of $\operatorname{Re}<2000$. The slope became moderate for higher Re. The transition to turbulent flow regime ${ }^{47}$, which was reported to occur in the region of $\operatorname{Re}>2100$, would be related to the analogous profiles. The tendency was similar to our previous report using microjet mixers ${ }^{27}$. Note that in the region of Re smaller than 400 , we could not observe complete decolorization within the straight channel of the device, which had a maximum length of $10 \mathrm{~cm}$. The results gave us two insights about the relationship between the scale of a mixer and the mixing time. First, scaling-down of the channel (i.e., usage of the microreactor) is desirable to achieve a fast mixing shorter than $10 \mathrm{~ms}$. The dramatic decrease in the mixing time was not achieved only by increasing the flow rate and Re. Second, the microscale is not necessarily needed for the reaction on a subsecond time scale. Tee-1.1 achieved mixing in 10-100 ms when the flow rate was higher than $50 \mathrm{~mL} \mathrm{~min}^{-1}$ and $\mathrm{Re}>1000$. Such a high flow rate would not suitable for the lab-scale experiment so that the use of microreactor will be the choice at the stage of the fundamental study. However, when the development for the industrial application starts and the reaction time is not as short as milliseconds, use of millireactor with intensified flow rate should be considered. Needless to say, the analysis for heat removal performance described in the following section should be conducted before changing the reactor size. 

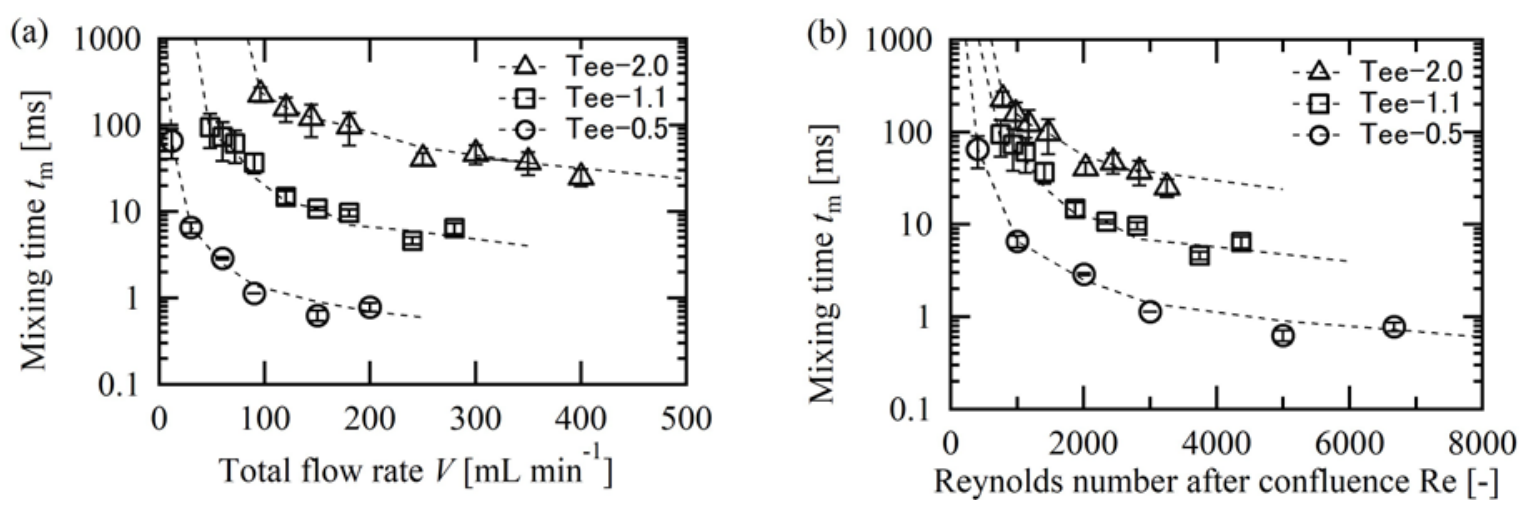

Figure 7. Mixing times obtained by measuring the lengths for decolorization with neutralization in three tee mixers against (a) flow rate and (b) Reynolds number. Dashed lines are shown for helping the readers' understanding of the tendency.

Heat removal performance dependent on the reactor scale. Next, we evaluated the influence of reactor size on the heat removal ability. Numerical calculations were employed for its accuracy in measuring the temperature profile inside the reactor. A simplified reactor model in which the reacting fluid flows inside an isothermal circular wall was employed. A dimensionless number $\beta$ was employed for analyzing the results. $\beta$ was previously used by Hartman et al. as the ratio of the heat generated in the reactor to the heat removed from the reactor ${ }^{48}$. They determined $\beta$ for the flow reactor as $\frac{-r \Delta H_{\mathrm{r}} d^{2}}{4 \Delta T_{\mathrm{ad}} \kappa}$, where $r$ is the reaction rate, $d$ is the reactor diameter, $\Delta T_{\mathrm{ad}}$ is the adiabatic temperature rise, and $\kappa$ is the thermal conductivity of the fluid. Here, we further modified and simplified $\beta$. First, the adiabatic temperature rise was obtained as

$$
\Delta T_{\mathrm{ad}}=\frac{\text { Total reaction enthalpy }}{\text { Heat capacity }}=\frac{-C_{\mathrm{A} 0} V \Delta H_{\mathrm{r}}}{\rho V c_{\mathrm{p}}}=\frac{-C_{\mathrm{A} 0} \Delta H_{\mathrm{r}}}{\rho c_{\mathrm{p}}}
$$


where $C_{\mathrm{A} 0}$ is the initial concentration of the main reactant, $\rho$ is the density, and $C_{\mathrm{p}}$ is the specific heat of the reaction media. Second, the reaction rate was substituted for the initial concentration of the reactant and kinetic constant $k$. In the case of the first-order reaction of the species A,

$$
r=k C_{\mathrm{A} 0}
$$

is used. Then, $\beta$ can be simplified as the ratio of the reaction rate to the thermal diffusion rate:

$$
\beta=\frac{-k C_{\mathrm{A}} \Delta H_{\mathrm{r}} d^{2}}{4 \frac{-C_{\mathrm{A}} \Delta H_{\mathrm{r}}}{\rho c_{\mathrm{p}}} \kappa}=\frac{k d^{2}}{4 \frac{\kappa}{\rho c_{\mathrm{p}}}}=\frac{k}{4 \alpha / d^{2}}=\frac{\text { reaction rate }}{\text { thermal diffusion rate }}
$$

where $\alpha$ is the thermal diffusivity defined as $\alpha=\frac{\kappa}{\rho C_{\mathrm{p}}}$.

Detailed derivation of $\beta$ from the original description and from the heat balance equation is described in the supporting information. Figure 8(a) shows the simulation results for the firstorder reaction with $\beta$ and the standardized maximum temperature rise $\Delta T_{\max } / \Delta T_{\mathrm{ad}}$, where $\Delta T_{\max }$ is the difference between the highest temperature in the simulated region and the temperature of the reactor wall. The example of the temperature profile in the reactor is presented in the supporting information. We would like to note that the obtained relationship between $\beta$ and $\Delta T_{\max } / \Delta T_{\mathrm{ad}}$ is universal at least for $E_{\mathrm{a}}=0$ because the other variables in the partial differential equations were negligible compared to $\beta$ (see the supporting information). When $\beta$ was 0.1 , the temperature rise was approximately $2 \%$ to the adiabatic condition, meaning that isothermal operation was almost achieved. The value of the activation energy did not make much difference when $\beta$ value was smaller than 1 . When the value of the $\beta$ increased to 10 and higher, $\Delta T_{\max } / \Delta T_{\mathrm{ad}}$ increased significantly. The slope of the curve was highly dependent on the activation energy, indicating the acceleration of reaction by heat generation. In the range $\beta>100$, 
$\Delta T_{\max } / \Delta T_{\text {ad }}$ went close to 1 even with zero activation energy. Figure 8(b) shows the results corresponding to the second-order reaction, in which $\beta$ was defined as $\frac{k C_{\mathrm{A} 0}}{4 \alpha / d^{2}}$. Similar curves with little bit smaller values of $\Delta T_{\max } / \Delta T_{\text {ad }}$ to the first-order reaction was obtained. We could derive the rules of thumb for analyzing the heat removal performance of microreactors as follows:

1) Setting the diameter for satisfying $\beta<1$ is effective for successful heat removal. If possible, $\beta$ $<0.1$ can create an almost isothermal condition.

2) With $\beta$ value larger than 10 , heat removal becomes difficult. If $\beta$ is larger than 100 , the reaction proceeds in an almost adiabatic manner.

Although more detailed analysis and formulation based on the mathematical discussion were conducted previously ${ }^{39}$, we decided to propose these simplified rules for practical usage in organic chemistry. Mathematical treatment for the activation energy requires coupling of the temperature rise and activation energy so that the activation energy becomes prerequisite of the analysis. Determination or estimation of the activation energy is very difficult and hardly done during the development of organic reactions. Considering that activation energy had little effect in the range of $\beta<1$ and $\beta>100$, performance analysis without considering the activation energy can provide easy and practical criteria for determining the size of microreactors.

Figure 8 (c) is the diagram of the value of $\beta$ to the reactor diameter and the rate constant calculated from the definition. The $\alpha$ value of water at $20^{\circ} \mathrm{C}$ was used for the calculation. The time for achieving $99 \%$ conversion is displayed as the reaction completion time $t_{99}$ at the left axis. For the same $\beta$ value, $t_{99}$ for the second-order reaction was about 20 times larger than that for the first-order reaction. Heat removal of the second-order reaction is harder than the first-order 
reaction because of the higher initial reaction rate. $\beta$ was larger than 10 with $d=1.0 \mathrm{~mm}$ and a kinetic constant of $1.0 \mathrm{~s}^{-1}$, implying that the isothermal operation was difficult with a milliscale reactor for a fast reaction which has a time scale of seconds. In contrast, with $d=0.2 \mathrm{~mm}, \beta$ was smaller than 1.0 even with $k=10 \mathrm{~s}^{-1}$, implying that the microreactor could handle the heat of a reaction with a timescale of seconds or less. However, $k$ over $1000 \mathrm{~s}^{-1}$ resulted in $\beta$ of approximately 100 even with a 0.2 mm reactor diameter. By comparing Figure 7 and 8, we could say that achieving short mixing time is far easier than keeping isothermal operation with fast reaction. For example, a reactor with $1 \mathrm{~mm}$ i.d. can realize $10 \mathrm{~ms}$ mixing time from Figure 7 but $\beta$ for reaction in $10 \mathrm{~ms}$ with $1 \mathrm{~mm}$ i.d. is around several hundred or higher from Figure 8.

We would like to emphasize that whether the large $\beta$ value is allowed or prohibited depends on the employed reaction system and reactant concentrations. If the concentration is moderate and the reaction has little sensitivity to the temperature, adiabatic operation with $\beta>100$ has little effect on the reaction. On the other hand, if the reactant solution is dense and the reaction is sensitive on the temperature, even $\beta=1$ would not be acceptable because it still causes about 20\% temperature rise to the adiabatic situation.

In the case of scaling-up of fast reactions, we propose the assessment method based on the evaluation of $\beta$. First, estimate the value of $\beta$ with the current reactor diameter, reaction time, and reasonable reaction order. Then, the following criteria can be used.

1) If $\beta$ is smaller than 0.1 , reactor diameter can be safely enlarged within the range satisfying $\beta$ $<0.1$.

2) If $\beta$ is already higher than 100 , it means that reaction proceeds almost in adiabatic condition. Even though the current results may be influenced by reaction heat, there would be no more 
influence of the reaction heat emerging with scaling-up. If the current reaction performance is fair enough, the maximum diameter of the reactor can be determined only by the mixing performance.

3) If $\beta$ falls in the range of $0.1<\beta<100$, a small change of the reactor diameter can affect the reaction significantly. Further assessment on the temperature sensitivity is recommended before scaling-up.

The calculation in this work intentionally neglected the effect of channel structures on the heat transfer ability. It is reported that a well-designed channel structure can make a complicated flow profile to obtain a several-fold higher heat transfer coefficient than the straight channel ${ }^{49}$. If the estimated $\beta$ value is between 0.1 and 100 and the reaction is sensitive to the temperature, it would be important to consider optimizing channel geometry. Unfortunately, the interplay among channel structure, flow profiles, and heat transfer is too complicated ${ }^{50,51}$ to include in the discussion in this work. 

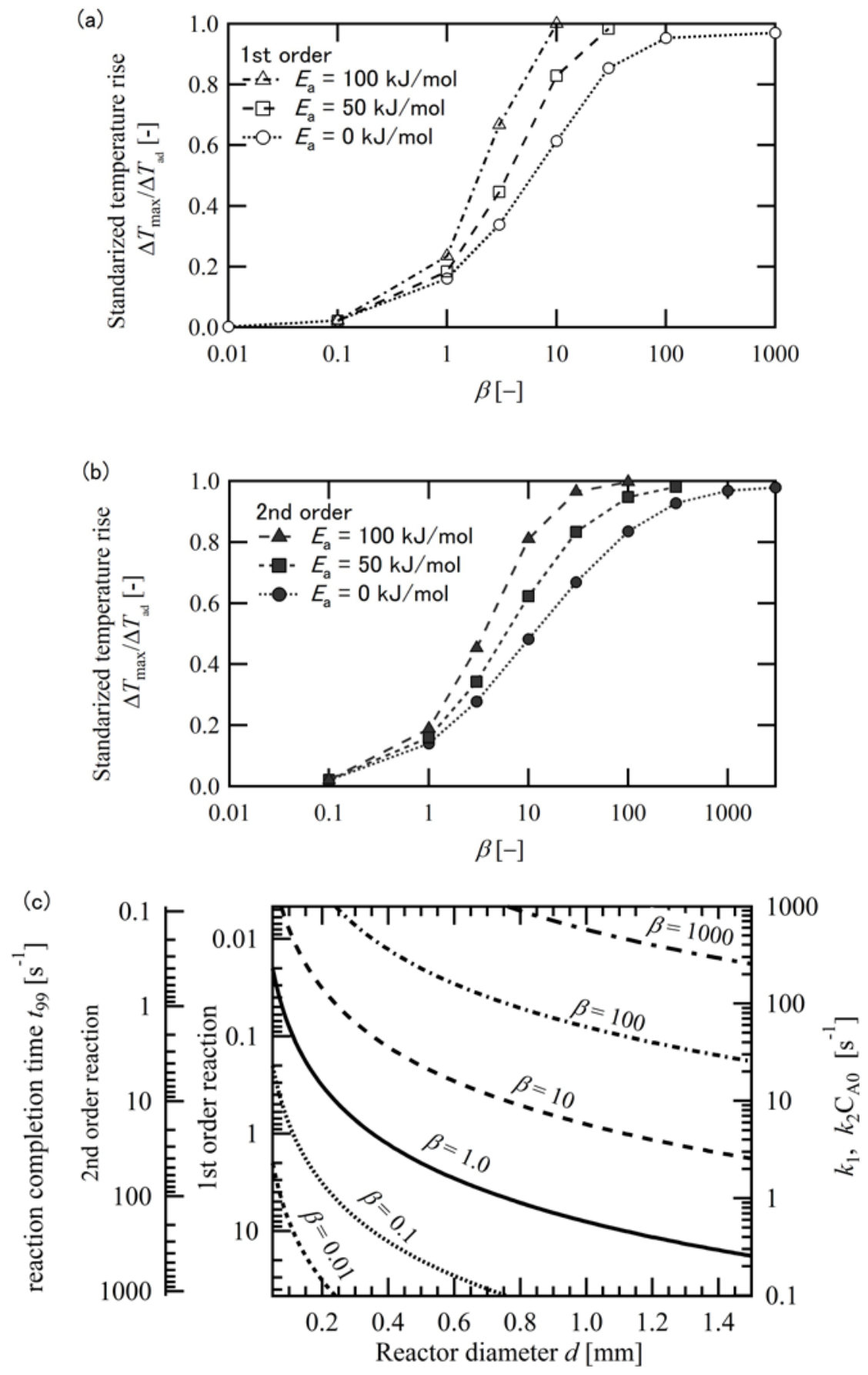

Figure 8. Effect of the scale of a reactor on the reaction heat removal: (a) relationship between the dimensionless number $\beta$ and the maximum temperature rise in the reactor for the first-order reaction, and (b) for the second-order reaction; and (c) $\beta$ value for various reactor dimensions and a kinetic constant of the reaction with $\alpha=1.43 \times 10^{-7} \mathrm{~m}^{2} \mathrm{~s}^{-1}$. 
Case study with ultrafast organolithium reaction. Here, we discuss the possibility of enlarging the size of the microreactor employed for the ultrafast reaction shown in Scheme 2. A reaction time within a few milliseconds is needed for conducting this reaction system because intermediate $p$-APLi decomposes quickly even at the reaction temperature of $-70^{\circ} \mathrm{C}$. Kim et al. ${ }^{13}$ achieved successful synthesis utilizing a specially integrated microreactor with a diameter of $0.25 \mathrm{~mm}$ and length of $1.0 \mathrm{~cm}$. Under the best conditions with a $76 \%$ yield, a $1.5 \mathrm{~ms}$ reaction time was realized by a total flow rate of $23.6 \mathrm{~mL} \mathrm{~min}^{-1}$. The product throughput was $0.055 \mathrm{~mol} \mathrm{~h}^{-}$ ${ }^{1}$ in this condition.

First, we determined the maximum diameter satisfying the mixing requirement. During scalingup of the system, the mixing time must be kept within a few milliseconds. Judging from Figure 7, a reactor diameter of $0.5 \mathrm{~mm}$, which is twice the original diameter, can achieve mixing within 1 ms with a large enough Re. Then, we conducted an assessment on the reaction heat removal based on the criteria discussed in the previous sub-section. Table 1 shows the estimated value of $\beta$ and the maximum temperature rise for the halogen-lithium exchange reaction between $p$-IAP and MesLi. In spite of the small diffusion length in the reactor Kim et al. employed, the reaction in milliseconds went beyond the heat removal capacity to result in a very high $\beta$ value and a nonnegligible temperature rise. The assumptions used in the calculation are explained in the supporting information. This situation is classified as case 2) in the previous discussion. So, the maximum reactor diameter was determined to be $0.5 \mathrm{~mm}$ by the mixing requirement. With a diameter of $0.5 \mathrm{~mm}$, the calculated $\beta$ value went even higher than 2000 , but the temperature rise in estimation itself changed little compared to the original condition.

Figure 9 shows the results of our experiment conducted using a reactor system with an optimized diameter of $0.5 \mathrm{~mm}$. The commercial tees and tubing for liquid chromatography were used for 
constructing the reactor system. The original results by Kim et al. using an integrated reactor with an inner diameter of $0.25 \mathrm{~mm}$ are presented together. Both reactors provided almost the same yield in the examined range of residence times. Re in our reactor was calculated to be 6300 for the operating condition with the shortest residence time of 2 ms. It satisfied the operation range for complete mixing in milliseconds shown in Figure 7. The conversion of $p$-IAP was greater than 99\% under all conditions, indicating that mixing was completed within the reactor. Residence times shorter than 2 ms could not be evaluated due to the limitation of the pump flow rate and the minimum reactor length achieved with the commercial tees and tubing. In our best condition, the total flow rate was $213 \mathrm{~mL} \mathrm{~min}^{-1}$, and the product throughput was $0.44 \mathrm{~mol} \mathrm{~h}^{-1}$, which was 8 times higher than in the original condition.

Table 1. $\beta$ parameters and expected temperature rise for the halogen-lithium exchange reaction in this study

\begin{tabular}{ccc}
\hline Reactor diameter $[\mathrm{mm}]$ & $\beta[-]$ & Expected maximum \\
& & temperature rise [K] \\
\hline 0.25 (Kim et al.) & 566 & 7.9 \\
0.50 (This study) & 2262 & 8.1 \\
\hline
\end{tabular}




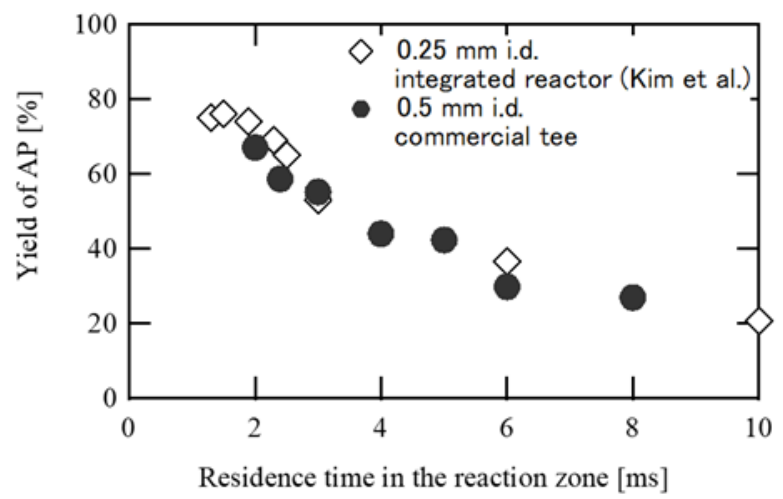

Figure 9. Results of the protecting-group-free organolithium reaction with different reactor sizes.

\section{CONCLUSIONS}

In this paper, we quantified the relationship between the mixing rate and the observable reaction kinetics, the mixing performance depending on the reactor size, and the heat removal performance derived from the reaction rate and the reactor diameter. We proposed strategies for conducting fast chemical reactions utilizing microreactors based on the above models and results. To conduct reaction rate analysis, the required mixing performance can be determined from the chart using the Damköhler number. If the mixing performance is not sufficient for the target reaction, the observable kinetic constant must be smaller than the true one. For scaling-up fast chemical reactions conducted in microreactors, the maximum reactor scale that maintains the reaction condition can be determined from the mixing time and the expected maximum temperature rise. The dimensionless number $\beta$ is useful for estimating the temperature rise in the reactor. If $\beta$ in the original condition is smaller than 0.1 , the maximum reactor diameter should be the one that obtains a value of $\beta=0.1$. If $\beta$ in the original condition is larger than 100 , it implies that a further increase of $\beta$ with the reactor scale would affect the reaction little. The 
scale-up strategy was demonstrated successfully with the protecting-group-free halogen-lithium exchange reaction. We optimized the reactor size to be $0.50 \mathrm{~mm}$ for maximizing the throughput while keeping the original reaction performance. In our previous study, we proposed and demonstrated the concept of numbering-up the micromixers after maximizing the throughput of each channel within the pressure drop limitation ${ }^{27}$. The strategy would be more practically used with the mixing time measurement and heat removal analysis presented in this study. This study proved that the throughput of several hundred $\mathrm{mL} / \mathrm{min}$ in one microchannel is possible. Numbering-up of the microchannels, whose diameters are optimally determined, will be able to produce a feasible amount of chemicals for industrial scale.

For future studies, reaction optimization for an ultra-fast reaction based on detailed kinetics and reaction mechanisms should be challenged. In this work, we employed THF for the solvent in the organolithium reaction for comparing the reactor performance with the literature. THF is a good solvent for activating the organolithium species ${ }^{52}$, but it would also activate the side-reaction so that as low temperature as $-70^{\circ} \mathrm{C}$ is needed. Other solvents with less activation effect, such as tetrahydropyran and diethyl ether would allow the higher reaction temperature and make the process more industrially feasible. However, screening with varying all of the solvents, reactant concentrations, reaction temperature, and a reaction time is obviously highly cost consuming approach. Kinetic analysis with considering the reaction pathways and the agglomeration of lithiated compounds would be essential for determining the best condition in a vast reaction space. In-situ analysis tools with microreactors such as $\mathrm{NMR}^{53}$ and FT-IR ${ }^{54}$ may provide important scientific knowledge and idea on such a complicated reaction system. 


\section{Supporting Information.}

The following file is available free of charge.

Mixing time measurement from the decolorization length

Mesh discretization and temperature contour in FLUENT

Derivation of dimensionless variables

Calculation method of $k_{\mathrm{obs}}$

Estimation of $\beta$ for the halogen-lithium exchange reaction (PDF).

\section{AUTHOR INFORMATION}

\section{Corresponding Author}

* E-mail: shusaku_asano@cm.kyushu-u.ac.jp

Current address: Institute for Materials Chemistry and Engineering, Kyushu University

6-1, Kasuga-koen, Kasuga, Fukuoka 816-8580, Japan

\section{Notes}

The authors declare no competing financial interest.

\section{ACKNOWLEDGMENT}

This work was supported by the Japan Society for the Promotion of Science (JSPS), grant numbers 25220913 and 15J00287. We thank Dr. Tadahisa Sato for the discussion on the industrialization of the microreaction technology. We also thank Dr. Aiichiro Nagaki, Mr. Kengo Sasatsuki, Ms. Yoko Aizawa, Dr. Shin-ichiro Ishida and Dr. Nobuhiko Nishitani for their kind instructions regarding laboratory techniques in organic chemistry. 


\section{NOMENCLATURE}

\section{Symbols}

$c_{\mathrm{p}} \quad$ specific heat capacity of the fluid $\left[\mathrm{J} \mathrm{kg}^{-1} \mathrm{~K}^{-1}\right]$

$C_{j} \quad$ molar concentration of species $j\left[\mathrm{~mol} \mathrm{~m}^{-3}\right]$

$C_{j 0} \quad$ initial concentration of species $j$ in the reactor $\left[\mathrm{mol} \mathrm{m}^{-3}\right]$

$d \quad$ reactor diameter $[\mathrm{m}]$

D diffusion coefficient $\left[\mathrm{m}^{2} \mathrm{~s}^{-1}\right]$

$t_{\text {mix }} \quad$ mixing time calculated by the decolorization length [s]

t99 reaction completion time in which $99 \%$ of the reactant is consumed [s]

$T_{0} \quad$ temperature of the reactor inlet

$\Delta T_{\mathrm{ad}} \quad$ adiabatic temperature rise [K]

$\Delta T_{\max }$ maximum temperature rise in the reactor $[\mathrm{K}]$

$\Delta H_{\mathrm{r}} \quad$ reaction enthalpy $\left[\mathrm{J} \mathrm{mol}^{-1}\right]$

$H \quad$ Hight of the reactor channel [mm]

$k \quad$ rate constant of the first order or of the second order reaction $\left[\mathrm{s}^{-1}\right.$, or m$\left.^{3} \mathrm{kmol}^{-1} \mathrm{~s}^{-1}\right]$

$k_{\text {obs }} \quad$ observable rate constant affected by mixing $\left[\mathrm{s}^{-1}\right.$, or $\mathrm{m}^{3} \mathrm{kmol}^{-1} \mathrm{~s}^{-1}$ ]

$l_{\text {mix }} \quad$ decolorization length $[\mathrm{mm}]$

$r \quad$ reaction rate $\left[\mathrm{kmol} \mathrm{m}^{-3}\right]$

$V_{\text {ave }} \quad$ average velocity of the fluid $\left[\mathrm{m} \mathrm{s}^{-1}\right]$

Re Reynolds number [-]

$W_{2 \mathrm{D}} \quad$ Width of the fluid lamellae $[\mu \mathrm{m}]$

W Width of the reactor channel [mm]

\section{Greek Symbols}

$\alpha \quad$ thermal diffusivity $\left[\mathrm{m}^{2} \mathrm{~s}^{-1}\right]$

$\beta \quad$ ratio of reaction rate to thermal diffusion rate [-]

$\eta \quad$ effectiveness factor of the homogeneous reaction [-] 
$\kappa \quad$ thermal conductivity $\left[\mathrm{W} \mathrm{\textrm {m } ^ { - 2 }} \mathrm{K}^{-1}\right]$

$\rho \quad$ density of fluid $\left[\mathrm{kg} \mathrm{m}^{-3}\right]$

$\mu \quad$ viscosity of fluid [Pa s]

$\phi \quad$ Damköhler number [-]

\section{REFERENCES}

(1) Elvira, K. S.; I Solvas, X. C.; Wootton, R. C. R.; Demello, A. J. The Past, Present and Potential for Microfluidic Reactor Technology in Chemical Synthesis. Nat. Chem. 2013, 5 (11), 905-915. https://doi.org/10.1038/nchem.1753.

(2) Jensen, K. F. Flow Chemistry-Microreaction Technology Comes of Age. AIChE J. 2017, 63 (3), 858-869. https://doi.org/10.1002/aic.15642.

(3) Sato, T. New Synthetic Method of Nanoparticles by Micro Chemical Process Technology. Fujifilm Res. Dev. (in Japanese) 2008, 53 (53), 21-26.

(4) Nagasawa, H.; Aoki, N.; Mae, K. Design of a New Micromixer for Instant Mixing Based on the Collision of Micro Segments. Chem. Eng. Technol. 2005, 28 (3), 324-330. https://doi.org/10.1002/ceat.200407118.

(5) Yasukawa, T.; Ninomiya, W.; Hoshino, M. Chapter 3. Prospects for Practical Applications of Flow Microreactor Synthesis. 2017, pp 107-118.

(6) Yasukawa, T.; Ninomiya, W.; Ooyachi, K.; Aoki, N.; Mae, K. Efficient Oxidative Dehydrogenation of Lactate to Pyruvate Using a Gas-Liquid Micro Flow System. Ind. Eng. Chem. Res. 2011, 50 (7), 3858-3863. https://doi.org/10.1021/ie102043a.

(7) Wang, K.; Li, L.; Xie, P.; Luo, G. Liquid-liquid Microflow Reaction Engineering. React. Chem. Eng. 2017, 2, 611-627. https://doi.org/10.1039/C7RE00082K.

(8) Behnam, M.; Stelzer, T.; Snead, D. R.; Chen, J.; Beingessner, R. L.; Weeranoppanant, N.; Jamison, T. F.; Adamo, A.; Myerson, A. S.; Revalor, E. M.; et al. On-Demand 
Continuous-Flow Production of Pharmaceuticals in a Compact, Reconfigurable System. Science (80-. ). 2016, 352 (6281), 61-67. https://doi.org/10.1126/science.aaf1337.

(9) Watanabe, S.; Ohsaki, S.; Hanafusa, T.; Takada, K.; Tanaka, H.; Mae, K.; Miyahara, M. T. Synthesis of Zeolitic Imidazolate Framework-8 Particles of Controlled Sizes, Shapes, and Gate Adsorption Characteristics Using a Central Collision-Type Microreactor. Chem. Eng. J. 2017, 313, 724-733. https://doi.org/10.1016/j.cej.2016.12.118.

(10) Sebastián, V.; Jensen, K. F. Nanoengineering a Library of Metallic Nanostructures Using a Single Microfluidic Reactor. Nanoscale 2016, 8 (33), 15288-15295.

https://doi.org/10.1039/c6nr04104c.

(11) Yoshida, J. I.; Takahashi, Y.; Nagaki, A. Flash Chemistry: Flow Chemistry That Cannot Be Done in Batch. Chem. Commun. 2013, 49 (85), 9896-9904. https://doi.org/10.1039/c3cc44709j.

(12) Nagaki, A.; Kim, H.; Yoshida, J. I. Aryllithium Compounds Bearing Alkoxycarbonyl Groups: Generation and Reactions Using a Microflow System. Angew. Chemie - Int. Ed. 2008, 47 (41), 7833-7836. https://doi.org/10.1002/anie.200803205.

(13) Kim, H.; Nagaki, A.; Yoshida, J. I. A Flow-Microreactor Approach to Protecting-GroupFree Synthesis Using Organolithium Compounds. Nat. Commun. 2011, 2 (1), 264-266. https://doi.org/10.1038/ncomms1264.

(14) Nagaki, A.; Kim, H.; Moriwaki, Y.; Matsuo, C.; Yoshida, J. I. A Flow Microreactor System Enables Organolithium Reactions without Protecting Alkoxycarbonyl Groups. Chem. - A Eur. J. 2010, 16 (36), 11167-11177. https://doi.org/10.1002/chem.201000876.

(15) Webb, D.; Jamison, T. F. Diisobutylaluminum Hydride Reductions Revitalized: A Fast, Robust, and Selective Continuous Flow System for Aldehyde Synthesis. Org. Lett. 2012, 14 (2), 568-571. https://doi.org/10.1021/ol2031872.

(16) Zaborenko, N.; Murphy, E. R.; Kralj, J. G.; Jensen, K. F. Synthesis and Kinetics of Highly Energetic Intermediates by Micromixers: Direct Multistep Synthesis of Sodium 
Nitrotetrazolate. Ind. Eng. Chem. Res. 2010, 49 (9), 4132-4139.

https://doi.org/10.1021/ie100263p.

(17) Eyholzer, M.; Schenkel, B.; Rittiner, B.; Penn, G.; Noti, C.; Sedelmeier, G.; Irle, E.;

Roberge, D. Control of Hazardous Processes in Flow: Synthesis of 2-Nitroethanol. J. Flow Chem. 2013, 4 (1), 26-34. https://doi.org/10.1556/jfc-d-13-00016.

(18) Shimizu, M.; Yamataka, H. Direct Rate Measurements of the Reactions of Benzophenone with RMgX and RLi: Effects of Substituents and Reagent Concentration on Rates. Bull. Chem. Soc. Jpn. 2004, 77 (9), 1757-1761. https://doi.org/10.1246/bcsj.77.1757.

(19) Paul, E. L.; Atiemo-Obeng, V. A.; Kresta, S. M. Handbook of Industrial Mixing; 2004. https://doi.org/10.1002/0471451452.

(20) Bourne, J. R.; Kut, O. M.; Lenzner, J.; Maire, H. Kinetics of the Diazo Coupling between 1-Naphthol and Diazotized Sulfanilic Acid. Ind. Eng. Chem. Res. 1990, 29 (9), 1761-1765. https://doi.org/10.1021/ie00105a004.

(21) Fournier, M.-C.; Falk, L.; Villermaux, J. A New Parallel Competing Reaction System for Assessing Micromixing Efficiency_Experimental Approach. Chem. Eng. Sci. 1996, 51 (22), 5053-5064. https://doi.org/10.1016/0009-2509(96)00270-9.

(22) Schwolow, S.; Hollmann, J.; Schenkel, B.; Röder, T. Application-Oriented Analysis of Mixing Performance in Microreactors. Org. Process Res. Dev. 2012, 16 (9), 1513-1522. https://doi.org/10.1021/op300107z.

(23) Pinot, J.; Commenge, J. M.; Portha, J. F.; Falk, L. New Protocol of the VillermauxDushman Reaction System to Characterize Micromixing Effect in Viscous Media. Chem. Eng. Sci. 2014, 118, 94-101. https://doi.org/10.1016/j.ces.2014.07.010.

(24) Krupa, K.; Nunes, M. I.; Santos, R. J.; Bourne, J. R. Characterization of Micromixing in T-Jet Mixers. Chem. Eng. Sci. 2014, 111, 48-55. https://doi.org/10.1016/j.ces.2014.02.018.

(25) Falk, L.; Commenge, J. M. Performance Comparison of Micromixers. Chem. Eng. Sci. 2010, 65 (1), 405-411. https://doi.org/10.1016/j.ces.2009.05.045. 
(26) Plasari, E.; Bertrand, M.; Lamarque, N.; Lebaigue, O.; Ducros, F. Micromixing Characterisation in Rapid Mixing Devices by Chemical Methods and LES Modelling. Chem. Eng. J. 2015, 283, 462-475. https://doi.org/10.1016/j.cej.2015.07.022.

(27) Asano, S.; Yamada, S.; Maki, T.; Muranaka, Y.; Mae, K. Design Protocol of Microjet Mixers for Achieving Desirable Mixing Times with Arbitrary Flow Rate Ratios. React. Chem. Eng. 2017, 2 (6), 830-841. https://doi.org/10.1039/c7re00051k.

(28) Kölbl, A.; Kraut, M. On the Use of the Iodide Iodate Reaction Method for Assessing Mixing Times in Continuous Flow Mixers. AIChE J. 2011, 57 (4), 835-840. https://doi.org/10.1002/aic.12313.

(29) Asano, S.; Maki, T.; Mae, K. Evaluation of Mixing Profiles for a New Micromixer Design Strategy. AIChE J. 2016, 62 (4), 1154-1161. https://doi.org/10.1002/aic.15082.

(30) Ma, C. Y.; Chen, M.; Wang, X. Z. Modelling and Simulation of Counter-Current and Confined Jet Reactors for Hydrothermal Synthesis of Nano-Materials. Chem. Eng. Sci. 2014, 109, 26-37. https://doi.org/10.1016/j.ces.2014.01.006.

(31) Kölbl, A.; Kraut, M.; Wenka, A. Design Parameter Studies on Cyclone Type Mixers. Chem. Eng. J. 2011, 167 (2-3), 444-454. https://doi.org/10.1016/j.cej.2010.08.092.

(32) Aoki, N.; Umei, R.; Yoshida, A.; Mae, K. Design Method for Micromixers Considering Influence of Channel Confluence and Bend on Diffusion Length. Chem. Eng. J. 2011, 167 (2-3), 643-650. https://doi.org/10.1016/j.cej.2010.08.084.

(33) Baldyga, B.; Bourne, J. R.; Walker, B. Non-Isothermal Micromixing in Turbulent Liquids. Can. J. Chem. Eng. 1998, 76 (641).

(34) Johnson, B. K.; Prud'homme, R. K. Chemical Processing and Micromixing in Confined Impinging Jets. AIChE J. 2003, 49 (9), 2264-2282. https://doi.org/10.1002/aic.690490905.

(35) Anxionnaz, Z.; Cabassud, M.; Gourdon, C.; Tochon, P. Heat Exchanger/Reactors (HEX Reactors): Concepts, Technologies: State-of-the-Art. Chem. Eng. Process. Process Intensif. 2008, 47 (12), 2029-2050. https://doi.org/10.1016/j.cep.2008.06.012. 
(36) Kölbl, A.; Kraut, M. Characterization of a Temperable Mixer with the Acetal Cleavage Method. Chem. Eng. J. 2013, 227, 22-33. https://doi.org/10.1016/j.cej.2012.11.124.

(37) Kockmann, N.; Roberge, D. M. Scale-up Concept for Modular Microstructured Reactors Based on Mixing, Heat Transfer, and Reactor Safety. Chem. Eng. Process. Process Intensif. 2011, 50 (10), 1017-1026. https://doi.org/10.1016/j.cep.2011.05.021.

(38) Usutani, H.; Tomida, Y.; Nagaki, A.; Okamoto, H.; Nokami, T.; Yoshida, J. I. Generation and Reactions of O-Bromophenyllithium without Benzyne Formation Using a Microreader. J. Am. Chem. Soc. 2007, 129 (11), 3046-3047. https://doi.org/10.1021/ja068330s.

(39) Kramers, H.; Westerterp, K. R. Elements of Chemical Reactor Design and Operation; Academic Press: New York, 1963.

(40) Hessel, V.; Hardt, S.; Löwe, H.; Schönfeld, F. Laminar Mixing in Different Interdigital Micromixers: I. Experimental Characterization. AIChE J. 2003, 49 (3), 566-577. https://doi.org/10.1002/aic.690490304.

(41) Rose, M. C.; Stuehr, J. Kinetics of Proton Transfer Reactions in Aqueous Solution. III. Rates of Internally Hydrogen-Bonded Systems. J. Am. Chem. Soc. 1968, 90 (26), 72057209. https://doi.org/10.1021/ja01028a005.

(42) Choi, S.; Karnik, R.; Langer, R.; Lim, J.-M.; Farokhzad, O. C.; Swami, A.; Wu, J.; Chopra, S.; Gilson, L. M. Ultra-High Throughput Synthesis of Nanoparticles with Homogeneous Size Distribution Using a Coaxial Turbulent Jet Mixer. ACS Nano 2014, 8 (6), 6056-6065. https://doi.org/10.1021/nn501371n.

(43) Pátek, J.; Hrub, J.; Klomfar, J.; Součková, M.; Harvey, A. H. Reference Correlations for Thermophysical Properties of Liquid Water at 0.1 MPa. J. Phys. Chem. Ref. Data 2009, 38 (1), 21-29. https://doi.org/10.1063/1.3043575.

(44) Levenspiel, O. Chemical Reaction Engineering, 3rd Edition; John Wiley \& Sons, Inc., 1998. 
(45) Aoki, N.; Fukuda, T.; Maeda, N.; Mae, K. Design of Confluence and Bend Geometry for Rapid Mixing in Microchannels. Chem. Eng. J. 2013, 227, 198-202. https://doi.org/10.1016/j.cej.2012.03.061.

(46) Dreher, S.; Kockmann, N.; Woias, P. Characterization of Laminar Transient Flow Regimes and Mixing in T-Shaped Micromixers. Heat Transf. Eng. 2009, 30 (1-2), 91-100. https://doi.org/10.1080/01457630802293480.

(47) Bird, R. B.; Stewart, W. E.; Lightfoot, E. N. Transport Phonomena, Revised 2n.; John Wiley \& Sons, Inc., 2006.

(48) Hartman, R. L.; McMullen, J. P.; Jensen, K. F. Deciding Whether to Go with the Flow: Evaluating the Merits of Flow Reactors for Synthesis. Angew. Chemie - Int. Ed. 2011, 50 (33), 7502-7519. https://doi.org/10.1002/anie.201004637.

(49) Mielke, E.; Plouffe, P.; Koushik, N.; Eyholzer, M.; Gottsponer, M.; Kockmann, N.; MacChi, A.; Roberge, D. M. Local and Overall Heat Transfer of Exothermic Reactions in Microreactor Systems. React. Chem. Eng. 2017, 2 (5), 763-775. https://doi.org/10.1039/c7re00085e.

(50) Zheng, Z.; Fletcher, D. F.; Haynes, B. S. Transient Laminar Heat Transfer Simulations in Periodic Zigzag Channels. Int. J. Heat Mass Transf. 2014, 71, 758-768. https://doi.org/10.1016/j.ijheatmasstransfer.2013.12.056.

(51) Schwolow, S.; Ko, J. Y.; Kockmann, N.; Röder, T. Enhanced Heat Transfer by Exothermic Reactions in Laminar Flow Capillary Reactors. Chem. Eng. Sci. 2016, 141, 356-362. https://doi.org/10.1016/j.ces.2015.11.022.

(52) Stanetty, P.; Mihovilovic, M. D. Half-Lives of Organolithium Reagents in Common Ethereal Solvents. J. Org. Chem. 1997, 62 (5), 1514-1515. https://doi.org/10.1021/jo961701a.

(53) Rehm, T. H.; Hofmann, C.; Reinhard, D.; Kost, H. J.; Löb, P.; Besold, M.; Welzel, K.; Barten, J.; Didenko, A.; Sevenard, D. V.; et al. Continuous-Flow Synthesis of Fluorine- 
Containing Fine Chemicals with Integrated Benchtop NMR Analysis. React. Chem. Eng. 2017, 2 (3), 315-323. https://doi.org/10.1039/C7RE00023E.

(54) Perro, A.; Lebourdon, G.; Henry, S.; Lecomte, S.; Servant, L.; Marre, S. Combining Microfluidics and FT-IR Spectroscopy: Towards Spatially Resolved Information on Chemical Processes. React. Chem. Eng. 2016, 1 (6), 577-594. https://doi.org/10.1039/c6re00127k. 